\title{
Tackling Economic Deceleration: A puzzle for Beijing
}

\section{Agatha Kratz}

Translator. Marie-Eve Reny

\section{(Q) OpenEdition \\ Journals}

\section{Electronic version}

URL: http://journals.openedition.org/chinaperspectives/6052

DOI: 10.4000/chinaperspectives.6052

ISSN: 1996-4617

\section{Publisher}

Centre d'étude français sur la Chine contemporaine

\section{Printed version}

Date of publication: 7 December 2012

Number of pages: $73-75$

ISSN: 2070-3449

\section{Electronic reference}

Agatha Kratz, «Tackling Economic Deceleration: A puzzle for Beijing », China Perspectives [Online], 2012/4 | 2012, Online since 01 December 2012, connection on 15 September 2020. URL : http:// journals.openedition.org/chinaperspectives/6052 


\section{Tackling Economic Deceleration: A puzzle for Beijing}

\section{Analysis by Agatha Kratz based on:}

- "The Current State of the Housing Price Maintenance Project," Editorial, Xinshiji, 23 July 2012.

- Chen Lu, (1) "Wen Jiaobao: Eliminating Real Estate Speculation Necessitates a Long-term Strategy," Caixinwang, 8 July 2012.

- Lin Jinbing, (2) "The Decline in Interest Rates in China and Europe Could Affect Coordination Efficiency," Caixinwang, 6 July 2012.

- You Xi, (3) "Increasing Liquidities," Caijing, 15 July 2012.

- Yu Bin, (4) "Aiming for Average Growth Stability," Caijing, 15 July 2012.

- Yang Zhongxu, (5) "The Deflationary Burst Is on Its Way," Caijing, 15 July 2012.

$\mathrm{T}$ he health of China's economy has deteriorated these past months, and the quarterly statistics published in July have been the most critical since 2009. (6) In the context of such market strains, will China's leaders be able to take the necessary measures to re-boost their country's economy?

A series of recently published articles shed light on China's current economic conditions, the policies implemented by Beijing to contain economic decline, and the resulting drop in trust it has generated. Reactions by analysts have been mitigated, and several hope for China to accelerate reforms to complement the temporary containment strategies adopted by Beijing.

\section{Disappointing economic indicators}

In an article published in Caijing on 15 July, Yang Zhongxu gauges the state of China's economy in the earlier months of the year. The statistics published in early July by Beijing for the second trimester of 2012 were disappointing. Between April and July, China's GDP increased by only 7.6 percent. While this number would remain significant for any other country, it nonetheless challenged economic predictions, and came as a surprise following China's three consecutive years of growth in excess of 8 percent. Furthermore, the numbers published in July 2012 suggest that the decline will be more than temporary. Indeed, China's GDP growth in the first quarter also decelerated compared to the first quarter of 2011 , with a growth rate of only 7.8 percent. This announcement was accompanied by the publication of alarming statistics on China's inflation rate in June, which took the international economic community by surprise. According to these numbers, the Consumer Price Index (CPI) ${ }^{(7)}$ increased by only 2.2 percent during the first semester of 2012, compared with 3.3 percent in 2011. For the first time since 2009, China's economy is experiencing deflationary trends. Some analysts ${ }^{(8)}$ have voiced concerns that such a trend could get worse in the future, and claim that enterprises are experiencing decline in the prices of their goods on a daily basis.

The early July numbers on international trade are similarly disappointing. Industrial investments are stagnating, the demand for industrial loans has gone down considerably, profit margins in several sectors have declined, numerous state-owned enterprises have reported losses, and the Producer Price Index (PPI) (9) in July experienced a decrease for the fourth consecutive month as a result of low domestic demand, explains Yang Zhongxu.
While Yang Zhongxu claims that China's economic deceleration is now an uncontested reality, the extent of such a decline is subject to debate. Some analysts predict a smooth landing, while others fear a dramatic crash. China's economic situation nevertheless remains less critical than it was in 2009. During an interview with Yang Zhongxu, Liu Yuanchun, vice-president of Renmin University in Beijing, claims that while suggesting a decline in China's economy, the statistics of July 2012 are in no way as alarming as the numbers that followed the global financial crisis. Unlike the latter, the July 2012 numbers suggest that the economy is still growing.

In addition to economic deceleration, the renewed dynamism of real estate development has generated significant concern. In a speech later transcribed by Chen Lu, Premier Wen Jiabao explains that one of the Chinese government's main concerns is the real estate market. Indeed, following a notable slowdown in real estate transactions and the stabilisation of market prices due to regulatory policies, the price of property has increased again these last several months. Yang Zhongxu observes that real estate investments rose in May and increased by 9 percent compared to April. Moreover, numbers from the National Bureau of Statistics of China on 18 July, cited by Xinshiji in an editorial published on 23 July, confirm this trend. In July, China's real estate market was once again overheated.

1. Chen Lu is a Professor of economics and management at the University of Electronic Science and Technology of China.

2. Lin Jinbing is an intern at Caixin.

3. Youxi is a journalist at Caijing and for the Chinese edition of the New York Times.

4. Yu Bin is a researcher at the Development Research Center of China's State Council and is in charge of the Economic Research Department. He specialises in the study of macroeconomic policies, local and urban economies, and economic reforms.

5. Yang Zhongxu is a journalist at Caijing.

6. This opinion was voiced by the vice-president of Renmin University, Liu Yuanchun, who was interviewed by Yang Zhongxu.

7. CPI (Consumer Price Index): According to the French national statistics institute INSEE, "The CPI helps measure the inflation rate. It enables assessment of the average variation in the price of consumer goods and services purchased by households between two given periods of time. It is an estimated measure of the evolution of prices whose quality remains constant"; http://www.insee.fr/fr/methodes/default.asp?page=definitions/indice-prix-consommation.htm (consulted on 11 October 2012).

8. This includes Zhang Hanya, President of the Association of Chinese Investors (as cited by Yang Zhongxu).

9. PPI (Production Price Index): According to the French national statistics institute INSEE, "The PPI measures the evolution in the prices of goods received by domestic producers for their output and sold in China"; http://www.insee.fr/fr/methodes/default.asp?page=definitions/indice-prix-ala-production.htm (consulted on 11 October, 2012). 
These inflationary trends could potentially constitute a significant threat to China's economy. Beijing notably fears that prices may jump again and that speculation may resume. The latter scenario could nourish the country's current real estate bubble, which is already close to bursting. Wen thus calls for great vigilance and encourages heightened surveillance of the real estate market.

As noted by the 23 July Xinshiji editorial, ensuring a healthy real estate market at the national level is one of the central government's main priorities in years to come. Overcoming such a challenge will require making a choice between two potentially conflicting sets of interests: those of the central government, primarily concerned with macroeconomic stability and the socioeconomic well being of the population, and those of local governments and local enterprises, which directly benefit from the real estate market and its dynamism. These past years, local governments have indeed become significantly dependent upon revenues generated by real estate and land-related transactions. Such dependency has led to the making of risky decisions that have at times violated regulations established by Beijing. As such, the second challenge for the Centre will be to monitor the market closely with stricter regulatory policies, to ensure that its guidelines are enforced at the local level.

Finally, other concerns exacerbate these challenges. Yu Bin emphasises that local governments' financial situations deteriorated during the first semester of 2012, as fiscal and land-related revenues decreased substantially. This raises the risk of economic instability in China, especially in light of the increasing relationships of dependency that has emerged between banks, provincial governments, real estate companies, and indebted property purchasers over the years. Moreover, according to Yu Bin, the significant decline in China's domestic demand and the overall deterioration of the world economy have made some mainland industries worry about the threat of overproduction.

In light of such concerns, China's leaders, including Wen Jiabao, have frequently intervened nationally to reassure the population, the finance sector, industries, and investors of China's economic stability. According to Yang Zhongxu, Premier Wen organised a number of official meetings with representatives of all sectors of the economy to help gather opinions and suggestions on how to implement the most appropriate strategy to prevent instability.

The Chinese government finds itself in a delicate position insofar as it must accommodate two sets of conflicting interests, namely boosting the economy while discouraging overly risky transactions and preventing the collapse of the real estate bubble.

\section{Double drop in interest rates}

Yang Zhongxu and You Xi observe that the Chinese government has deployed a series of macroeconomic measures to boost the economy and avoid the bursting of the real estate bubble. The most important such measure was a decision to reduce interest rates in July. That decision was made twice within a single month. Hence, rates on deposits at up to one year went down from 3.25 to 3.00 percent, and rates on loans at up to one year decreased from 6.31 to 6.00 percent. This type of government decision is rare and attests to the unusualness of the situation. As Yang Zhongxu explains, it surprised financial markets and failed to eliminate their existing concerns. You Xi notes that this kind of measure usually aims to respond to low levels of microeconomic financing and to reduce the debts of enterprises, local governments, and individual borrowers. More generally, the cen- tral government hopes that it will boost economic transactions by facilitating access to credit and reducing the cost of liquidities. These measures have already proven to be effective, as a number of provincial governments announced the launch of new investment programs in years to come. Such investments could in turn stimulate economic activity at the local level.

However, the government is reluctant to rely directly on the real estate sector to boost the economy. Chinese leaders have thus decided to reduce interest rates unevenly. As noted by Lin Jinbing, real estate interest rates have not decreased. This will help the government ensure recovery in some key sectors of the economy, while also avoiding overheating the real estate market.

In conjunction with the lowering of interest rates, the government has expressed its willingness to launch a series of social programs. These will be implemented in the months to come and are considered fundamental reforms by Premier Wen Jiabao. ${ }^{(10)}$ Premier Wen maintains that in light of the current state of the economy, investment projects must be "reasonable" (heli 合理). In the short-term, these investments will target infrastructurerelated projects: transportation networks, energy, electricity, sanitation, education, etc. Premier Wen also mentioned the building of subsidised housing. The government announced the construction of 4.6 million housing units since January 2012, and as of today, 2.6 million of them have been built. Chen Lu adds that the government has emphasised quality over quantity in this process.

Finally, Premier Wen has committed to taking necessary measures to contain the real estate market. As such, a number of policies aimed at regulating the sector more closely have been implemented. Moreover, to prevent further instances of speculation, a number of measures meant to control access to real estate loans have been strengthened. These include requirements as to the differentiation and quality of loans. Reforms in the real estate taxation system will also be pursued. Premier Wen concludes that the objective of such strategies is to embark on a path towards the progressive reduction of real estate prices.

\section{Reactions to measures taken by Beijing}

These measures have generated a diverse set of reactions in the Chinese media. While some analysts such as You Xi have welcomed the government's socially-oriented policies, many others do not hide their reservations. Most would nonetheless agree that the reduction of key interest rates can only be a short-term strategy and will not constitute a solution to some of the deeper imbalances characterising China's economy.

You Xi maintains that if a decrease in rates can help stimulate the economy in the short-term, it can also send contradictory signals in the long run and bias investment decisions. Furthermore, the author claims that a reduction in such rates cannot guarantee the country's economic redress. The latter would require cooperation from banks, which would be hard to obtain in a context of decline in economic trust. You Xi claims a reduction in banks' regulatory deposit ratio would constitute a more effective solution by freeing up liquidity more rapidly. Moreover, while boosting investments constitutes a solution, Premier Wen ${ }^{(11)}$ contends that the most important objective today is to ensure that future investments are reasonable. A simple policy aiming to reduce rates would not guarantee this goal.

10. Cited by You Xi.

11. Cited by Chen Lu. 
Lastly, You Xi adds that the government cannot keep on relying on banks when the country faces an economic slowdown, as this pattern feeds economic imbalance. Beijing's long-term objective should be the development and stimulation of consumption to turn investments into drivers of economic growth. China should aspire to transforming the structure of its economy, which the author views as unviable, and begin a gradual transition process towards a more quality-oriented development path. According to You Xi, in the short-term, the country should prioritise cultural irrigation projects, the building of subsidised housing (already planned by the government), social development programs, a reduction in carbon gas emissions, and investment in other strategic sectors of the economy. In the medium-term, China ought to stimulate investment in infrastructure optimisation projects, while also placing limits on the development of over-invested heavy industries. In the long run, China must pursue its transition towards a market economy and reduce the tax burden on small and medium enterprises. You Xi concludes that China's monetary policy should only be subsidiary and temporary, and should not constitute a substitute for a genuine long-term economic strategy.

Yang Zhongxu seconds You Xi on the importance of distinguishing shortand long-term strategies. According to Yang, China can no longer rely upon economic rate manipulations in the short-term. The government ought to demonstrate courage and implement reforms, especially in light of deteriorating international economic conditions in the medium-term. The author maintains that China must engage in a process of "creative destruction" to arrive at a new economic and development model. This creative process includes reforming the system of industrial monopolies, human and capital resources, the healthcare system, social security, the price system, stateowned enterprises, and the real estate sector.Yang Zhongxu adds that such policies may have short-term consequences insofar as they may distort the price system and financial incentives, and as a result lead to the overexploitation of natural resources and environmental destruction. Finally, the author notes that these policies have yet to bear fruit, as following the reduction in rates, China's stock market reported a significant decline. Moreover, in the past several months, the renminbi has similarly lost value.

In general, the above authors all conclude by calling for deepened reforms and a transformation of China's system towards a more sustainable economic structure, viable below the 8 percent growth rate threshold. This will require significant effort and constitute perhaps the greatest challenge for Beijing in the years to come.

\section{Translated by Marie-Eve Reny.}

